\title{
The psychological state and changes in the routine of the patients with rheumatic diseases during the coronavirus disease (COVID-19) outbreak in Turkey: a web-based cross-sectional survey
}

\author{
Emire Seyahi $^{1}$ (D) $\cdot$ Burc Cagri Poyraz $^{2}$ (D) $\cdot$ Necdet Sut $^{3}$ (D) $\cdot$ Selma Akdogan $^{4}$ (D) $\cdot$ Vedat Hamuryudan $^{1}$ (D)
}

Received: 20 May 2020 / Accepted: 12 June 2020 / Published online: 22 June 2020

(c) Springer-Verlag GmbH Germany, part of Springer Nature 2020

\begin{abstract}
We hypothesized that patients with rheumatic diseases (RD) would have increased psychological distress during the COVID19 outbreak; therefore, assessed their psychological symptoms and changes in their routine. A web-based questionnaire survey was conducted in a cross-sectional design in three groups of participants: (1.) patients with RD, (2.) hospital workers, and (3.) high-school teachers/academic staff. Psychiatric status was evaluated using Hospital Anxiety and Depression Scale and Impact of Event Scale-Revised scale. Overall response rate was 34.7\%. We studied 771 patients with RD, 535 hospital workers, and 917 teachers/academic staff. Most of the patients with RD were unwilling to go to the hospital (86\%), while $22 \%$ discontinued their medications. Biological DMARDS were the most frequent drugs whose doses were altered. Only $4 \%$ were willing to take hydroxychloroquine for protection. Moreover, the frequency of anxiety (20\%), depression (43\%), and post-traumatic stress (28\%) among patients with RD were found to be comparable to that found among the teachers/ academic staff (23\%, $43 \%$ and $29 \%$, respectively), whereas significantly less than that observed among the hospital workers $(40 \%, 62 \%$, and $46 \%$, respectively) $(p<0.001)$. Female gender, use of social media, having a comorbid disease, or a psychiatric disorder were found to be independently associated with psychiatric symptoms in total study population. The majority of the patients were unwilling to attend outpatient visits and one-fifth skipped or stopped their immunosuppressive agents. Psychiatric symptoms in patient's and teacher's populations were of considerable clinical concern, despite being significantly lower than that observed among the hospital workers.
\end{abstract}

Keywords COVID-19 $\cdot$ Outbreak $\cdot$ Health workers $\cdot$ Mental health $\cdot$ Anxiety $\cdot$ Depression $\cdot$ Post-traumatic stress $\cdot$ Sleep disorders $\cdot$ Rheumatology $\cdot$ Rheumatic diseases

Electronic supplementary material The online version of this article (https://doi.org/10.1007/s00296-020-04626-0) contains supplementary material, which is available to authorized users.

Emire Seyahi

eseyahi@yahoo.com

Burc Cagri Poyraz

bcpoyraz@yahoo.com

Necdet Sut

necdetsut@yahoo.com

Selma Akdogan

drslma.akdogan@gmail.com

Vedat Hamuryudan

vhamuryudan@yahoo.com

\section{Introduction}

Coronavirus disease (COVID-19) first identified in China in December 2019 resulted in a worldwide pandemic. The disease was confirmed to have reached Turkey on $11 \mathrm{March}$ 2020 [1]. By 1 April, it was confirmed that it had spread all

1 Cerrahpasa Medical Faculty, Department of Internal Medicine, Division of Rheumatology, Cerrahpasa Medical School, Istanbul University-Cerrahpasa, Istanbul 81310, Turkey

2 Cerrahpasa Medical Faculty, Department of Psychiatry, Division of Geriatric Psychiatry, Istanbul University-Cerrahpasa, Istanbul, Turkey

3 Department of Biostatistics and Medical Informatics, Trakya University Medical Faculty, Edirne, Turkey

4 Cerrahpasa Medical Faculty, Department of Internal Medicine, Istanbul University-Cerrahpasa, Istanbul, Turkey 
over the country [1]. Starting from March 16, 2020, Turkish government issued several restrictions to prevent the spread of the virus. First, schools and all public gathering places were closed and a permanent lockdown for elderly or with chronic illnesses was declared, this was followed by weekend curfews. Eligible hospitals were transformed into 'pandemic hospitals' [1]. Many inpatient clinics became care units for COVID-19 patients, elective surgical or interventional operations were postponed, and the performance of outpatient clinics was considerably reduced to prioritize the care of these patients. All these unprecedented measures have profoundly affected the health care system as well as the social life.

Several studies revealed that being older than 60 years, smoking and comorbid medical conditions such as cardiovascular disease, chronic lung disease, hypertension, diabetes mellitus, and obesity are the major contributors for the severe outcome among patients with COVID-19 [2]. Close monitoring of those with immunosuppression, cancer, and chronic renal disease is also warranted [2].

Since the time of the declaration of the first COVID-19 case, we have received several calls from our patients having a rheumatic diseases (RD) reflecting their concerns and fears regarding their compromised immune status. We, therefore, assessed the impact of the pandemic and its related control measures on the psychological state of patients with RD. As control groups, we investigated two different occupational groups: the first was hospital workers in whom a higher prevalence of psychological symptoms were observed during the COVID-19 outbreak [3-6]; and the other was high-school teachers or academic staff in whom we assumed that psychological symptoms would be less, given that they were working from home since the schools had been closed. Additionally, we investigated the immediate change in the routine concerning outpatient visits or regular use of drugs only among patients with RD.

\section{Patients and methods}

A web-based survey was conducted in a cross-sectional design using the Survey Monkey software (SurveyMonkey, San Mateo, CA, USA) and sent out to the participants via WhatsApp link. The study groups consisted of patients with $\mathrm{RD}$, hospital workers, and high-school teachers or academic staff. The online survey contained three parts. The first part included questions on socio-demographic and other variables. The second and third parts included the evaluation of psychological distress.

(a) Identification of socio-demographic variables and probable risk factors for COVID-19

Demographic data, age, gender, occupation, marital status, having child/children (yes or no), educational status, household size, source of information related with COVID19 , types of social media and, daily hours of TV/social media exposure were collected. Previous diagnosis with COVID-19 in the participant itself, in a close friend or in a family relative was sought. Participants were also asked whether they were smokers (active, quitted or never) and have been previously diagnosed with a comorbid disease (such as cardiovascular disease, chronic lung disease, hypertension, diabetes mellitus or else) and a psychiatric disorder or had previously used a psychiatric drug for at least 3 months.

The following questions were asked only to patients with RD. These were related with adherence to stay home warnings (loose, moderate, or strict); the obligation to go outside for work; satisfaction with the medical support or information received for COVID-19 (much, enough, not at all); visiting the outpatient clinic (regularly; as it was before; did not want to; wanted to but could not contact anyone; was advised not to come, or did not have a scheduled visit); proper use of the medications (yes, as it was before; yes, but decreased or skipped the dose; no, completely stopped); the type of medication the patient altered the dose of or stopped taking and thought about taking hydroxychloroquine for protective measures (yes, I recently started; yes I thought about it but I have some hesitations; I already take it as a prescribed drug; no, never thought about it) [7].

(b) Evaluation of the psychiatric symptoms

Anxious and depressive symptoms were assessed using Hospital Anxiety and Depression Scale (HADS), a 14-item questionnaire [8]. Scores for anxiety and depression were derived by summing the responses for each of the subscales (HADS-A and HADS-D). In addition, cut-off points of $\geq 11$ and $\geq 8$ were used for quantification of anxiety and depression, respectively. Symptoms of post-traumatic stress (PTS) were assessed using Impact of Event Scale-Revised (IES-R), a 22 item questionnaire $[9,10]$. This tool evaluates intrusion, avoidance, and hyperarousal in three subdimensions and presents a total score for subjective stress (IES-R score). A cut-off point of $\geq 33$ provided the best diagnostic accuracy for PTS (9-10). Both HADS and IES-R were validated previously in Turkish $[11,12]$. In addition, sleep problems were evaluated using two questions of IES-R; choosing'severe' or 'very severe' as an answer was considered as the presence of a trouble in maintaining sleep (no. 2) and trouble in falling asleep (no. 15).

The questionnaire prepared for patients with RD included 63 questions, while that prepared for the controls included 55. Participants who completely filled in either the HADS or the IES-R were found eligible for the study. 


\section{Identification and selection of the study population}

A flowchart shows the evolution of the study population (Supplement Fig. 1).

\section{Group 1: patients with RD}

We identified six subgroups of rheumatic diseases: (1) rheumatoid arthritis (RA); (2) connective tissue disease (CTD) which included systemic lupus erythematosus, systemic sclerosis and primary Sjögren syndrome; (3) spondylarthropathies (SpA); (4) Behçet's syndrome (BS); (5) familal Mediterranean fever (FMF); (6) vasculitis. Patients who were examined within the last 6 months in our outpatient clinic were identified and 300 patients from each subgroup were consecutively selected as the target study population. Physicians and nurses working in the rheumatology department have sent the questionnaire via WhatsApp link. Of the 1800 patients that have been targeted, 916 responded. Of these $145(15.8 \%)$ had missing data. Finally, 771 were found eligible for the study and the response rate was calculated as $42.8 \%$.

\section{Group 2: hospital workers}

The staff of a university hospital and two state hospitals in Istanbul, which became 'coronavirus pandemic hospitals' and all located in Istanbul were chosen as the target hospital workers population. Web-based questionnaire was sent to medical (700 doctors and 1400 nurses), and non-medical staff $(n=300)$ such as secretaries, security guards, caretakers, and lab workers. Of these 2400 hospital workers, 691 responded (missing data: 156; 22.6\%); however, only 535 were found suitable for the study. The response rate was $22.3 \%$.

\section{Group 3: teachers and academic staff}

This group included around 2000 high-school teachers from 50 high schools and 200 academic members from non-medical faculties. All teachers and academic personnel were living and studying in Istanbul. A total of 1135 responded. Excluding 218 (19.2\%) with missing data, 917 were left eligible for the study. The response rate was $41.7 \%$.

\section{Response rate}

Overall response rate was calculated as 34.7\% (2223/ 6400). That of the hospital workers (22.3\%) was significantly lower than that observed among patients with RD (42.8\%) and teachers/academic staff $(41.7 \%)(p<0.001)$. Of 2223 study participants who were found to be eligible for the study, 214 (9.6\%) fulfilled only HADS, 91 (4.1\%) fulfilled only IES-R, while the remaining 1918 fulfilled both HADS and IES-R.

The survey ran between 4 and 24 April, 2020.

\section{Ethical statement}

This study was approved by the Ethics Committee of I. U.-C., Cerrahpaşa Medical Faculty (21/05/2020-63,480). Electronic informed consent was presented on the first page of the survey citing that the survey is voluntary and participants could withdraw from the survey at any time.

\section{Statistical analysis}

Normality distribution of the numeric variables was tested by the Shapiro-Wilk test. Kruskal-Wallis test was used for comparison of IES-R and HAD scales' scores, and then Dunn's test with Bonferroni correction was used for multiple comparisons when the significantly meaningful difference was obtained. Categorical variables were compared using Pearson's Chi-square test. The Mann-Whitney $U$ test was used for comparison of the scale scores between medical and non-medical health workers. Reliability of the scales was assessed as Cronbach's alpha coefficient.

We also used multivariate logistic regression analysis with enter method to examine the relationships among 13 various socio-demographic or clinical risk factors and the presence or absence of anxiety, depression and PTS combining all three study groups. The reference categories were identified as: Group 2 for the group variable, male for gender, $>8$ years for education, married for marital status, none for having child, $\leq 3$ for household size, $\leq 1 \mathrm{~h}$ for duration of TV or social media exposure, no for the presence of COVID-19 in the participant or family, no for the presence of someone $\geq 65$ years in the household, never for smoking habit, no for the presence of comorbid diseases, and no for the history of psychiatric disorders or psychiatric drug use for at least three months. IBM SPSS Statistics for Windows, v.20.0 (IBM Corp., Armonk, NY, USA) was used in the statistical analysis. A $p$ value of less than 0.05 was accepted as statistical significance.

\section{Results}

In total, we studied in total $771(245 \mathrm{M} / 526 \mathrm{~F})$ patients with RD (Group 1), 535 (181 M/ 354 F) hospital workers (Group 2) and 917 (258 M/ $659 \mathrm{~F}$ ) teachers/academic staff (Group 3). Patients with RD were categorized into six subgroups: (1) RA $(n=131 ; 21 \mathrm{M} / 110 \mathrm{~F})$; (2) CTD $(n=171 ; 18 \mathrm{M} /$ $153 \mathrm{~F})$; (3) SpA $(n=102 ; 58 \mathrm{M} / 44 \mathrm{~F})$; (4) BS $(n=171$; $108 \mathrm{M} / 63 \mathrm{~F})$; (5) FMF ( $n=79 ; 21 \mathrm{M} / 58 \mathrm{~F})$; (6) Vasculitis 
( $n=117 ; 19 \mathrm{M} / 98 \mathrm{~F}$ ). Of these 771 patients, 21 were off drugs, while the remaining were prescribed one or more of the following drugs such as biological disease-modifying anti-rheumatic drugs (DMARDs) ( $n=317,42.3 \%)$, nonbiological DMARDs ( $n=441,58.7 \%)$, and prednisolone ( $n=340,45.3 \%$ ), at the time of the survey. Hydroxychloroquine $(n=198,25.7 \%)$ and colchicine $(n=194,25.9 \%)$ were also listed among the prescribed drugs.

Hospital workers included medical workers [doctors $(n=233 ; 94 \mathrm{M} / 139 \mathrm{~F})$ and nurses $(n=158 ; 16 \mathrm{M} / 142 \mathrm{~F})]$ and non-medical workers $(n=144 ; 71 \mathrm{M} / 73 \mathrm{~F})$. Group 3 included 851 (234 M/ $617 \mathrm{~F})$ high-school teachers and 66 (24 M/ $42 \mathrm{~F}$ ) academic personnel.

(1) Socio-demographic characteristics (Table 1)

Respondents were mostly female in all study groups, somewhat slightly more in teachers/academic staff group. Besides that, there were significant socio-demographic differences between the study groups. The most striking was that the patients with RD were significantly older and less educated compared to both hospital workers and teachers/ academic staff. Additionally, most of the patients with RD were married and had children and a household size of $\geq 4$. While TV and social media were the basic sources of information about COVID-19 for all study groups, hospital workers seemed to receive most of the information from their institution. Patients with RD appeared to use social media less frequently and to spend less hours watching TV or using social media when compared to the rest of the study groups.

(2) Frequency of COVID-19 diagnosis and the frequency of its potential risk factors (Table 2)

Those who contracted COVID-19 were significantly more common among the hospital workers and this was also true for the family members and or close friends who had been diagnosed with COVID-19. Groups were roughly balanced regarding the presence of a household member of $\geq 65$ years and the frequency of active smoking, while both risk factors were slightly higher in teachers/academic staff group. Patients with RD had the highest frequency of comorbid and psychiatric diseases, whereas teachers/academic staff had the lowest.
Table 1 Socio-demographic variables and resources of information about COVID

\begin{tabular}{|c|c|c|c|c|}
\hline & $\begin{array}{l}\text { Group } 1 \text { patients } \\
\text { with RD }(n=771)\end{array}$ & $\begin{array}{l}\text { Group } 2 \text { hospital } \\
\text { workers }(n=535)\end{array}$ & $\begin{array}{l}\text { Group } 3 \text { teachers/ } \\
\text { academic staff } \\
(n=917)\end{array}$ & $P$ \\
\hline Age, median (min-max), years & $42(16-81)$ & $31(19-58)$ & $35(21-79)$ & $<0.001^{* \dagger \S}$ \\
\hline Male/female, $n$ (rate) & $245 / 526(0.46)$ & $181 / 354(0.51)$ & $258 / 659(0.39)$ & 0.058 \\
\hline \multicolumn{5}{|l|}{ Educational status, $n(\%)$} \\
\hline Primary/middle school & $281(36.4)$ & $18(3.4)$ & $1(0.1)$ & \multirow[t]{2}{*}{$<0.001^{* \dagger \S}$} \\
\hline High school or higher & $490(75.6)$ & $517(96.6)$ & $916(99.9)$ & \\
\hline \multicolumn{5}{|l|}{ Marital status, $n(\%)$} \\
\hline Married & 701(69) & $284(53.3)$ & $602(66.2)$ & \multirow[t]{2}{*}{$<0.001^{* \S}$} \\
\hline Single & $171(31)$ & $249(46.7)$ & $308(33.7)$ & \\
\hline Have child, $n(\%)$ & $524(68.8)$ & $228(45.4)$ & $497(57.6)$ & $<0.001^{* \dagger \$}$ \\
\hline \multicolumn{5}{|l|}{ Household size, $n(\%)$} \\
\hline$\leq 3$ & $408(52.9)$ & $259(57.9)$ & $545(63.3)$ & \multirow[t]{2}{*}{$<0.001^{\dagger}$} \\
\hline$\geq 4$ & $363(47.1)$ & $188(42.1)$ & $316(36.7)$ & \\
\hline \multicolumn{5}{|c|}{ Source of information related to COVID- $19, n(\%)$} \\
\hline TV & $698(90.5)$ & $367(68.6)$ & $817(89.1)$ & $<0.001^{* \S}$ \\
\hline Social media & $479(62.1)$ & $397(74.2)$ & $824(89.9)$ & $<0.001^{* \dagger \varsigma}$ \\
\hline Institution & $79(10.2)$ & $443(82.8)$ & $224(24.4)$ & $<0.001^{* \dagger \S}$ \\
\hline Friends & $167(21.7)$ & $303(56.6)$ & $428(46.7)$ & $<0.001^{* \dagger \S}$ \\
\hline \multicolumn{5}{|l|}{ Social media resources } \\
\hline Instagram & $425(55.1)$ & $348(65.0)$ & $628(68.5)$ & $<0.001^{* \dagger}$ \\
\hline Twitter & $206(26.7)$ & $211(39.4)$ & $535(58.3)$ & $<0.001^{* \dagger \S}$ \\
\hline Facebook & $315(40.9)$ & $192(35.9)$ & $365(39.8)$ & 0.175 \\
\hline WhatsApp groups & $277(35.9)$ & $371(69.3)$ & $529(57.7)$ & $<0.001^{* \dagger \S}$ \\
\hline Internet websites & $344(44.6)$ & $349(65.2)$ & $610(66.5)$ & $<0.001^{*}$ \\
\hline \multicolumn{5}{|c|}{ Hours spent daily watching TV/using social media } \\
\hline$\leq 1 \mathrm{~h}$ & $335(43.5)$ & $142(26.5)$ & $238(26.0)$ & \multirow[t]{2}{*}{$<0.0001^{* i}$} \\
\hline$\geq 2$ hours & $436(56.5)$ & $393(73.5)$ & $679(74.0)$ & \\
\hline
\end{tabular}

$P^{*}$ Group 1 vs Group $2,{ }^{\dagger}$ Group 1 vs Group $3,{ }^{\S}$ Group 2 vs Group 3, Min minimum, Max maximum 
Table 2 COVID-19 diagnosis and risk factors for COVID-19

\begin{tabular}{|c|c|c|c|c|}
\hline & $\begin{array}{l}\text { Group } 1 \text { patients } \\
\text { with } \mathrm{RD}(n=771)\end{array}$ & $\begin{array}{l}\text { Group } 2 \text { hospital } \\
\text { workers }(n=535)\end{array}$ & $\begin{array}{l}\text { Group } 3 \text { teachers/aca- } \\
\text { demic staff }(n=917)\end{array}$ & $P$ \\
\hline Diagnosed with COVID-19 ( $n \%)$ & $4(0.5)$ & $14(2.6)$ & $3(0.3)$ & $<0.001^{* \S}$ \\
\hline Family relative or close friends diagnosed with COVID-19, $n(\%)$ & $92(11.9)$ & $174(32.8)$ & $88(9.7)$ & $<0.001^{* \dagger \S}$ \\
\hline $\begin{array}{l}\text { Presence of a relative in the household } \geq 65 \text { years of age, } n(\%) \\
\text { Smoking status, } n(\%)\end{array}$ & $367(48.0)$ & $274(51.6)$ & $525(57.6)$ & $<0.001^{\dagger}$ \\
\hline Active & $290(37.8)$ & $201(37.8)$ & $390(42.8)$ & $<0.001^{* \dagger}$ \\
\hline Quit & $125(16.3)$ & $40(7.5)$ & $74(8.1)$ & \\
\hline Never & $353(46.0)$ & $291(54.7)$ & $447(49.1)$ & \\
\hline Diagnosed previously with a comorbid disease, $n(\%)$ & $257(33.3)$ & $75(14.0)$ & $122(13.3)$ & $<0.001^{* \dagger}$ \\
\hline $\begin{array}{l}\text { History of psychiatric disorders or psychiatric drug use for at } \\
\text { least three months, } n(\%)\end{array}$ & $247(32.0)$ & $129(24.1)$ & $140(15.3)$ & $<0.001^{* \dagger \S}$ \\
\hline
\end{tabular}

$P *$ Group 1 vs Group 2, ${ }^{\dagger}$ Group 1 vs Group $3,{ }^{\S}$ Group 2 vs Group 3

(3) Socio-demographic characteristics and response to the outbreak between different types of rheumatic diseases (Table 3)

Patients with RA were the oldest, while patients with FMF were the youngest among the subgroups. Males were in the majority in SpA and BS, whereas females predominated in the remaining subgroups. It seemed that significant number of patients strictly adhered to stay home warnings ( $>89 \%$ ), while adherence was a bit less in the SpA and BS subgroups ( $82.4 \%$ and $81.3 \%$, respectively). This was also true for being obliged to go out for work which was significantly higher among patients with $\mathrm{SpA}$ (40.6\%) and BS (44.7\%), compared to the rest of the subgroups. Most of the patients in all subgroups $(\geq 74 \%)$ were satisfied with the medical support or information about COVID-19. After the outbreak, a small percentage of the

Table 3 Socio-demographic characteristics and immediate behavior change after the outbreak in different types of rheumatic diseases

\begin{tabular}{|c|c|c|c|c|c|c|c|c|}
\hline & Total $n=771$ & RA $n=131$ & CTD $n=171$ & $\operatorname{SpA} n=102$ & BS $n=171$ & FMF $n=79$ & Vasculitis $n=117$ & $P$ \\
\hline $\begin{array}{l}\text { Age, median }(\min -\max ), \\
\text { years }\end{array}$ & $42(16-81)$ & $52(21-81)$ & $42(18-79)$ & $40.5(23-71)$ & $40(16-63)$ & $28(18-66)$ & $46(19-76)$ & $<0.001$ \\
\hline Male/ female, $n(\%)$ & $245 / 526$ & $21 / 110$ & $18 / 153$ & $58 / 44$ & $108 / 63$ & $21 / 58$ & $19 / 98$ & $<0.001$ \\
\hline $\begin{array}{l}\text { Strict compliance with } \\
\text { 'stay home' warnings', } \\
n(\%)\end{array}$ & $678(88.2)$ & $122(93.8)$ & $152(89.4)$ & $84(82.4)$ & $139(81.3)$ & $72(91.1)$ & $109(93.2)$ & 0.002 \\
\hline $\begin{array}{l}\text { Need to go out for work, } \\
n(\%)\end{array}$ & $213(27.8)$ & $21(16.0)$ & $30(17.5)$ & $41(40.6)$ & $76(44.7)$ & $24(30.8)$ & $21(18.1)$ & $<0.001$ \\
\hline $\begin{array}{l}\text { Received enough medical } \\
\text { support or information, } \\
n(\%)\end{array}$ & $591(72.7)$ & $103(78.6)$ & $131(76.6)$ & $78(76.5)$ & $129(75.4)$ & $63(79.7)$ & $87(74.4)$ & 0.675 \\
\hline \multicolumn{9}{|c|}{ Attended the outpatient clinic, $n(\%)^{*}$} \\
\hline $\begin{array}{l}\text { Regularly, as it was } \\
\text { before }\end{array}$ & $55(14.4)$ & $6(10.7)$ & $5(6.2)$ & $10(20.8)$ & $14(16.1)$ & $4(12.1)$ & $16(20.8)$ & 0.119 \\
\hline Did not want to & $163(42.7)$ & $26(46.4)$ & $35(43.2)$ & $16(33.3)$ & $32(36.8)$ & $18(54.5)$ & $36(46.8)$ & \\
\hline $\begin{array}{l}\text { Wanted to but could not } \\
\text { contact anyone }\end{array}$ & $59(15.4)$ & $9(16.1)$ & $11(13.6)$ & $10(20.8)$ & $13(14.9)$ & $7(21.2)$ & $9(11.7)$ & \\
\hline Was advised not to come & $105(27.5)$ & $15(26.8)$ & $30(37.0)$ & $12(25.0)$ & $28(32.2)$ & $4(12.1)$ & $16(20.8)$ & \\
\hline \multicolumn{9}{|l|}{ Continued medications $* *$} \\
\hline Yes, as it was before & $582(77.6)$ & $104(81.3)$ & $142(85.5)$ & $44(46.3)$ & $132(79.5)$ & $67(84.8)$ & $93(80.2)$ & $<0.001$ \\
\hline $\begin{array}{l}\text { Yes but decreased or } \\
\text { skipped the dose }\end{array}$ & $123(16.4)$ & $19(14.8)$ & $21(12.7)$ & $28(29.5)$ & $22(13.3)$ & $12(15.2)$ & $21(18.1)$ & \\
\hline No, stopped taking them & $45(6.0)$ & $5(3.9)$ & $3(1.8)$ & $23(24.2)$ & $12(7.2)$ & 0 & $2(1.7)$ & \\
\hline
\end{tabular}

$R A$ rheumatoid arthritis, $C T D$ connective tissue diseases, $S p A$ spondylarthropathies, $B S$ Behçet's syndrome, $F M F$ familial Mediterranean fever, Min minimum, Max maximum, $*_{n}=382, * * n=750$ 
patients who had a scheduled outpatient visit $(\mathrm{n}=382)$ attended the outpatient-clinic 'as it was before' (14.4\%) and this was similar among all subgroups. The remaining

Table 4 The prescribed drugs and those whose doses were either skipped or stopped

\begin{tabular}{lllr}
\hline Drugs & $\begin{array}{l}\text { Dose decreased, } \\
\text { skipped or stopped, } \\
n\end{array}$ & $\begin{array}{l}\text { Total pre- } \\
\text { scribed, } n\end{array}$ \\
& & & \\
\hline Biological DMARDs & & 191 & 34.6 \\
$\quad \begin{array}{l}\text { Anti-tumor necrosis factor } \\
\quad \text { agents }\end{array}$ & 66 & 24 & 29.2 \\
Tocilizumab & 7 & 15 & 40.0 \\
Anti-IL-1 agents & 6 & 75 & 6.7 \\
Rituximab & 5 & 9 & 33.3 \\
Interferon & 3 & & \\
Non-biological DMARDs & & 187 & 9.6 \\
Azathioprine & 18 & 149 & 8.0 \\
Methotrexate & 12 & 26 & 7.7 \\
Leflunomide & 2 & 29 & 20.7 \\
Mycophenolate mofetil/ & 6 & & \\
$\quad$ sodium & & 69 & 8.7 \\
Sulfasalazine & 6 & & \\
Others & & 340 & 9.4 \\
Corticosteroids & 32 & 198 & 10.6 \\
Hydroxychloroquine & 21 & 194 & 9.8 \\
Colchicine & 19 & 12 & 25.0 \\
Cyclophosphamide & 3 & & \\
\hline & & &
\end{tabular}

$D M A R D s$ disease-modifying anti-rheumatic drugs either 'did not want to come' (42.7\%), 'wanted to come but could not contact anyone in the hospital' (15.4\%), or was advised to postpone their visits (27.5\%). A significant number of patients continued their medications (582/750; $77.6 \%$ ), while only $16.4 \%$ (123/750) decreased or skipped their dose and 6.0\% (45/750) stopped taking them. This trend was almost similar among all study groups, except patients with SpA whose $53.7 \%$ discontinued or stopped taking their medications.

(4) Medications that are decreased in dosage/ skipped or stopped (Table 4)

Biological DMARDs were the most frequent drugs which patients decreased their dose, skipped or stopped taking (anti-IL-1 agents: $40 \%$, anti-TNF agents: $34.6 \%$, interferon: $33.3 \%$, tocilizumab $29.2 \%$, rituximab: $6.7 \%$ ). Prednisolone (low dose), azathioprine, methotrexate, leflunomide, colchicine, and sulfasalazine were least likely ( $\leq 10 \%$ for each drug) to be skipped or stopped. It has to be noted that among 198 patients who were regular users of hydroxychloroquine, 21 reported that they had to skip or stop the drug due to shortage or failure of prescription renewal.

A total of 753 patients responded to the 'Plaquenil' question. A great majority of the patients $(539 / 753 ; 71.6 \%)$ have not attempted to take hydroxychloroquine for protective measures, while $1.1 \%(8 / 753)$ had started taking it recently and $2.5 \%(19 / 753)$ were willing to take it despite having hesitations. The remaining $(187 / 753 ; 24.8 \%)$ were already regular users of hydroxychloroquine.

(5) Psychological symptoms (Table 5)

Table 5 Psychiatric symptoms

\begin{tabular}{|c|c|c|c|c|}
\hline & $\begin{array}{l}\text { Group } 1 \text { Patients with } \\
\text { RD } n=771\end{array}$ & $\begin{array}{l}\text { Group } 2 \text { Hospital work- } \\
\text { ers } n=535\end{array}$ & $\begin{array}{l}\text { Group } 3 \text { teachers/academic } \\
\text { staff } n=917\end{array}$ & $P$ \\
\hline HAD anxiety level, median (min-max) & $7(0-20)$ & $9(0-21)$ & $7(0-21)$ & $<0.001 * \S$ \\
\hline$\geq 11$ cut-off, $n(\%)$ & $148(19.6)$ & $200(39.8)$ & $202(23.1)$ & $<0.001 * \S$ \\
\hline HAD depression level, median (min-max) & $7(0-21)$ & $9(0-21)$ & $7(0-19)$ & $<0.001 * \S$ \\
\hline$\geq 8$ cut-off, $n(\%)$ & $324(42.8)$ & $309(61.6)$ & $373(42.7)$ & $<0.001 * \S$ \\
\hline IES-R (total), median (min-max) & $22(0-77)$ & $31(0-79)$ & $24(0-81)$ & $<0.001 * \S$ \\
\hline Intrusion & $6(0-29)$ & $10(0-32)$ & $7(0-29)$ & $<0.001 * \S$ \\
\hline Avoidance & $11(0-28)$ & $12(0-28)$ & $12(0-31)$ & $0.012 \dagger$ \\
\hline Hyperarousal & $5(0-24)$ & $8(0-24)$ & $5(0-24)$ & $<0.001 * \S$ \\
\hline PTS cut-off $(\geq 33)$ & $210(28.4)$ & $219(46.4)$ & $232(29.1)$ & $<0.001 * \S$ \\
\hline \multicolumn{5}{|l|}{ Sleep disturbances, $n(\%)$} \\
\hline Trouble staying asleep & $175(23.7)$ & $139(29.4)$ & $128(16.0)$ & $<0.001 * \dagger \S$ \\
\hline Trouble falling asleep & $176(23.8)$ & $139(29.4)$ & $145(18.2)$ & $<0.001 * \dagger \S$ \\
\hline Is the outbreak dangerous? $n(\%)$ & & & & $0.001 * \S$ \\
\hline Very dangerous & $681(88.3)$ & $432(81.2)$ & $792(86.6)$ & \\
\hline Partly or no dangerous at all & $90(11.7)$ & $103(18.8)$ & $125(13.4)$ & \\
\hline
\end{tabular}

$R D$ rheumatic disease, HADS Hospital anxiety and depression scale, IES-R impact of event scale-revised version, PTS post-traumatic stress $P^{*}$ Group 1 vs Group $2,{ }^{\dagger}$ Group 1 vs Group $3,{ }^{\S}$ Group 2 vs Group 3 
Both HADS and IES-R exhibited high internal consistency; Cronbach's alpha coefficients were 0.896 and 0.893 , respectively for HADS and IES-R.

Anxiety, depression, and IES-R scores of the patients with RD (Group 1) were found similar when compared to that of the teachers/academic staff (Group 3), whereas significantly lower when compared with that of the hospital workers (Group 2). The same holds true for all subdimensions of IES-R, except avoidance which was evenly distributed among the study groups while being slightly higher in Group 3. Although the hospital workers had the highest scores in both HADS and IES-R as well as the highest frequency rates of anxiety (39.8\%), depression (61.6\%), and PTS $(46.4 \%)$ as determined by the cut-off values, they still thought significantly less that the outbreak was very dangerous. The frequency of sleep problems in patients with RD was significantly higher than that of the teachers/academic staff, but then again, significantly lower than that reported in the hospital workers. These results were also true when we excluded those with a previous history of psychiatric disorder or the use of psychiatric drug for at least 3 months.

Additionally, all psychological symptoms were similar in frequency among the subgroups in Group 1 and between medical and non-medical hospital workers in Group 2 (data not shown).
It has to be noted that anxiety, depression, and PTS symptoms above the severity threshold for clinical concern were not infrequent in Group 1 and Group 3. They had a prevalence of $19.6 \%, 42.8 \%$, and $28.4 \%$ respectively, in Group 1 and a prevalence of $23.1 \%, 42.7 \%$, and $29.1 \%$ respectively, in Group 3. The same holds true for the sleep problems.

\section{Risk factors associated with psychological symptoms (Table 6)}

Of the 13 probable risk factors that were entered to the multivariate logistic regression model, seven variables (groups, age, gender, hours spent watching TV or using social media, diagnosis of COVID-19 in the participant or in a relative or close friend, presence of a comorbid or psychiatric disorder) were found to be independently associated with at least one of the psychological symptoms. According to these analyses, female gender, working in a hospital, a lower level of education, having a child, living in a crowded family, watching TV or social media for $\geq 1 \mathrm{~h}$, contracting COVID-19 (the participant itself, family relative or a close friend), being a smoker (either currently or in the past), having a comorbid disease, and a history of psychiatric illness increase the odds ratios of psychiatric symptoms during the COVID-19 outbreak. Although being elderly emerged as an independent

Table 6 Effect of socio-demographic variables, resources of information about COVID-19, COVID-19 diagnosis, and risk factors for COVID19 on anxiety, depression, and IES-R

\begin{tabular}{|c|c|c|c|c|c|c|}
\hline & \multicolumn{2}{|c|}{ HADS-anxiety $\geq 11$} & \multicolumn{2}{|c|}{ HADS-depression $\geq 8$} & \multicolumn{2}{|l|}{ IES-R $\geq 33$} \\
\hline & OR $(95 \% \mathrm{CI})$ & $P$ & OR $(95 \% \mathrm{CI})$ & $P$ & OR $(95 \% \mathrm{CI})$ & $\mathrm{P}$ \\
\hline \multicolumn{7}{|l|}{ Groups } \\
\hline Group 1 (patients with RD) & $0.39(0.28-0.54)$ & $<0.001$ & $0.52(0.39-0.70)$ & $<0.001$ & $0.45(0.33-0.62)$ & $<0.001$ \\
\hline Group 3 (teachers/academic staff) & $0.50(0.37-0.67)$ & $<0.001$ & $0.52(0.40-0.68)$ & $<0.001$ & $0.51(0.38-0.69)$ & $<0.001$ \\
\hline Age, 1 year increase & $0.95(0.93-0.96)$ & $<0.001$ & $0.97(0.96-0.98)$ & $<0.001$ & $0.97(0.95-0.98)$ & $<0.001$ \\
\hline Gender, being female & $3.07(2.29-4.12)$ & $<0.001$ & $1.57(1.27-1.95)$ & $<0.001$ & $2.54(1.97-3.29)$ & $<0.001$ \\
\hline Length of education, $\leq 8$ years & $1.60(1.07-2.40)$ & 0.023 & $1.11(0.80-1.53)$ & 0.548 & $1.78(1.24-2.54)$ & 0.002 \\
\hline Marital status, being single & $0.81(0.58-1.11)$ & 0.190 & $0.84(0.64-1.10)$ & 0.216 & $0.99(0.73-1.33)$ & 0.944 \\
\hline Have child, yes & $1.59(1.11-2.26)$ & 0.011 & $1.17(0.88-1.58)$ & 0.283 & $1.59(1.14-2.20)$ & 0.006 \\
\hline Household size, $\geq 4$ & $1.32(1.04-1.68)$ & 0.022 & $1.12(0.92-1.37)$ & 0.262 & $0.96(0.77-1.20)$ & 0.710 \\
\hline Time spent watching TV or using social media, $>1 \mathrm{~h}$ & $1.44(1.10-1.88)$ & 0.008 & $1.33(1.07-1.65)$ & 0.010 & $1.43(1.12-1.83)$ & 0.004 \\
\hline $\begin{array}{l}\text { Presence of COVID-19 in the participant, or in family or } \\
\text { close friends, Yes }\end{array}$ & $1.52(1.13-2.04)$ & 0.005 & $1.48(1.13-1.95)$ & 0.005 & $1.31(0.99-1.75)$ & 0.062 \\
\hline $\begin{array}{l}\text { Presence of a relative in the household } \geq 65 \text { years of age, } \\
\text { Yes }\end{array}$ & $1.17(0.93-1.48)$ & 0.190 & $1.24(1.02-1.5)$ & 0.033 & $1.19(0.96-1.48)$ & 0.108 \\
\hline Smoking status, Active or quit & $1.25(0.99-1.58)$ & 0.057 & $1.39(1.14-1.69)$ & 0.001 & $1.38(1.11-1.72)$ & 0.004 \\
\hline Comorbid diseases, Yes & $1.45(1.11-1.89)$ & 0.006 & $1.67(1.33-2.10)$ & $<0.001$ & $1.55(1.21-1.99)$ & $<0.001$ \\
\hline $\begin{array}{l}\text { History of psychiatric disorders or psychiatric drug use for } \\
\text { at least } 3 \text { months, Yes }\end{array}$ & $1.95(1.50-2.54)$ & $<0.001$ & $1.38(1.09-.74)$ & 0.008 & $1.49(1.16-1.92)$ & 0.002 \\
\hline
\end{tabular}

Reference categories are as follows: Group 2 (hospital workers) for Group variable, 1 year decrease for age, being male for gender, $>8$ years for length of education, being married for marital status, no for having child, $\leq 3$ for household size, $\leq 1 \mathrm{~h}$ for time spent watching TV or using social media, no for presence of COVID-19 in the participant or family, no for the presence of a relative in the household of $\geq 65$ years of age, never for smoking status, none for comorbid diseases, and none for history of psychiatric disorders or psychiatric drug use for at least 3 months 
protective risk factor, its effect seems to be considerably weak with an odds ratio of 0.95 for 1 year increase (CI 95\% $0.93-0.96)$.

\section{Discussion}

This cross-sectional web-based survey done in a large population during the first month of COVID-19 outbreak revealed rather important findings. Faced with an unprecedented situation, patients with RD tried to adapt expectedly by changing their routine: $85.6 \%$ were unwilling to attend outpatient visits, $88.2 \%$ complied strictly with the restrictions, and $22.4 \%$ discontinued or stopped their medications. They seemed to be satisfied with the medical support/information and were unwilling to use 'hydroxychloroquine' which became increasingly attractive during the COVID-19 outbreak [7]. The frequency of the psychological symptoms among patients with RD was similar to that found among teachers/academic staff, whereas significantly lower than that observed among the hospital workers. Nevertheless, anxiety, depression, and PTS levels defined as above the severity threshold for clinical concern were not infrequent in patient's and teacher's population. Significant anxiety was reported by one-fifth, significant depressive symptoms by a nearly half and PTS by one-third of the patients. The same holds true for the sleep problems, for which more than $20 \%$ in the sample reported at least severe or very severe degree of trouble. These findings indicate a significant traumatic impact of COVID-19 pandemic and related control measures over psychological well-being of individuals in a deeply affected city.

Additionally, being female, having a lower level of education, having a child, living in a crowded family, using social media/TV for $\geq 1 \mathrm{~h}$, having been diagnosed with COVID19 (participant itself or family relative/close friend), having a comorbid disease or a previous psychiatric diagnosis were found to be independent risk factors associated with the increased PTS, anxiety and depression in our total study population, in line with the previous reports $[6,13-20]$. These findings essentially emphasize a higher risk for certain individuals for psychological distress during the pandemic, based on their pre-trauma features such as gender, education and psychiatric or medical history, as well as features such as trauma directness, personal victimization of the individual and close relatives and the amount of exposure through TV and social media. Of concern, the latter two can become particularly fertile grounds for anxiety-provoking information and disinformation during a pandemic.

We observed that patients with SpA and BS were less likely to comply strictly to 'stay home' restrictions and more likely to go out for work, most probably due to the male predominance and relatively younger age. Additionally, it was not surprising to see that SpA subgroup which is usually treated with anti-TNF agents was the only subgroup in which regular drug use had been considerably disrupted. Biological DMARDs were by far the most frequent drugs which patients skipped or stopped completely. Another important finding of the study is that patients in the great majority quite possibly consider low-dose prednisolone and many of the non-biological DMARDs 'safe' since the discontinuation rate was only $<10 \%$ for each of the drug. It has to be noted that of the regular users of hydroxychloroquine, $10.6 \%$ who skipped or stopped it reported that their action was due to the shortage of the drug or failure of prescription renewal. On the other hand, of those who were non-users of hydroxychloroquine, very few $(<5 \%)$ were interested in taking it for protective measures, thinking probably that it was unsafe.

We would have expected that patients with RD to have higher levels of anxiety or depression because of the several potential risk factors. Much to our surprise, the level of their psychological distress did not significantly differ from that of the teachers/academic staff, a group which we assumed to be unlikely to be exposed to trauma that the frontline healthcare workers are encountering, and which, therefore, would show less severe distress. This finding may suggest that patients with RD might have developed a positive adaptation to the stressors related to having a chronic disease with unpredictable exacerbations and remissions for many years, and became more resilient to further stressors concerning health. Compared to teachers and academic staff group, patients with RD reported having more sleep problems, which in our opinion could be related with increased frequency of psychiatric disorders, problems of pain and/or increased frequency of regular prednisolone use.

In line with what we have found, health workers had high prevalence rates of severe insomnia, anxiety, depression, somatization, and obsessive-compulsive symptoms during the ongoing COVID-19 pandemic, as reported in several studies $[3-6,15,20]$.This was also evident with previous outbreaks such as that of SARS and MERS-Cov [21-24]. The reluctance of hospital workers to participate in our study as observed by the lower response rate could be also interpreted as a reflection of their low mood. Interestingly, contrary to what have been reported, the level of psychological distress did not differ between medical and non-medical hospital workers in our survey [15].

Our analysis based on subscales of IES-R revealed that healthcare workers had significantly higher scores in intrusion and hyperarousal subscales, whereas comparable scores with other groups in the avoidance subscale. The latter includes items concerning avoidance of certain situations, feeling, and ideas related to a previous traumatic event. For healthcare workers who are actively working on the frontline, avoidance of traumatic places, conditions, and content may not be an option. 
Previous studies revealed that after natural disasters, PTS was frequent in the victims with a prevalence ranging from 5 to $60 \%$ in the first 1-2 years [25]. Studies conducted after 2003 SARS outbreak revealed significant PTS symptoms in survivors, hospital workers, quarantined individuals as well as general population in severely affected areas [26-32]. Similar finding are being reported for the recent COVID-19 pandemic with consequences surpassing even the former SARS outbreak [32-34]. In line with the literature, symptoms of PTS in our study reveal further an ensuing increased psychiatric risk which could follow in the aftermath of COVID-19 pandemic.

This study has several limitations. We were not able to evaluate the psychological state before the outbreak. It is difficult to make causal inferences. There is possibility of selection bias. The sampling of our study was voluntary; therefore, those who had been severely affected mentally may not be available for the evaluation. Due to the sociocultural differences, our results may not be generalized. Absence of a disease control group could be another limitation. Finally, while we think that our results reflect the immediate response of the population as the survey was done 3 weeks after the outbreak, it could be rather difficult to discriminate the effect of the lockdown itself from that of the COVID-19 outbreak.

\section{Conclusions}

During the first month of the COVID-19 outbreak, most of the patients with RD could not attend outpatient visits. About one-fifth discontinued or stopped their medications. The level of psychiatric distress observed among patients with RD was comparable to that among teacher's/ academic staff, whereas significantly less when compared to that among hospital workers. Yet, significant anxiety reported by a fifth, depression by nearly a half, and PTS by a third of both patient's and teacher's population were of considerable concern indicating significant traumatic impact of COVID-19 pandemic on general population. Additionally, female gender, lower level of education, a crowded family, social media use, having a close friend or a family relative who had been diagnosed with COVID19 , smoking, having a comorbid disease, or a psychiatric disorder were found to be independently associated with psychiatric symptoms during the COVID-19 outbreak.

Acknowledgements The authors thank Serdal Ugurlu, MD, Selma Karagoz, MD, Sinem Nihal Esatoglu, MD, Ali Cetin Ezber, Ali Serdar Seker, Dilsen Cevirgen, Unal Sarıtac, Sultan Tura, Kader Bilgen and Adem Cetin for their effort in reaching the participants and Edward Tony Karakas for English editing.
Author contributions All authors contributed to the study conception and design. Material preparation, data collection, and analysis were performed by Emire Seyahi, Burc Cagri Poyraz, Necdet Sut, Selma Akdogan and Vedat Hamuryudan. The first draft of the manuscript was written by Emire Seyahi and all authors commented on previous versions of the manuscript. All authors read and approved the final manuscript.

Funding The authors have not received any financial support.

Conflict of interest Emire Seyahi, Burc Cagri Poyraz, Necdet Sut, Selma Akdogan, and Vedat Hamuryudan declare that they have no conflict of interest.

\section{References}

1. https://en.wikipedia.org/wiki/COVID-19_pandemic_in_Turkey

2. Gandhi RT, Lynch JB, Del Rio C (2020) Mild or moderate Covid19. N Engl J Med. https://doi.org/10.1056/NEJMcp2009249

3. Chew NWS, Lee GKH, Tan BYQ et al (2020) A multinational, multicentre study on the psychological outcomes and associated physical symptoms amongst healthcare workers during COVID19 outbreak. Brain Behav Immun. https://doi.org/10.1016/j. bbi.2020.04.049

4. Sun N, Wei L, Shi S et al (2020) A qualitative study on the psychological experience of caregivers of COVID-19 patients. Am J Infect Control. https://doi.org/10.1016/j.ajic.2020.03.018

5. Xiao H, Zhang Y, Kong D, Li S, Yang N (2019) The effects of social support on sleep quality of medical staff treating patients with coronavirus disease (COVID-19) in january and february 2020 in China. Med Sci Monit https://doi.org/10.12659/ MSM.923549

6. Lai J, Ma S, Wang Y et al (2020) Factors associated with mental health outcomes among health care workers exposed to coronavirus disease 2019. JAMA Netw Open. https://doi.org/10.1001/ jamanetworkopen.2020.3976

7. Graef ER, Liew JW, Putman MS et al (2020) COVID-19 global rheumatology alliance. Festina lente: hydroxychloroquine, covid19 and the role of the rheumatologist. Ann Rheum Dis. https://doi. org/10.1136/annrheumdis-2020-217480

8. Smarr KL, Keefer AL (2011) Measures of depression and depressive symptoms: Beck Depression Inventory-II (BDI-II), Center for Epidemiologic Studies Depression Scale (CES-D), Geriatric Depression Scale (GDS), Hospital Anxiety and Depression Scale (HADS), and Patient Health Questionnaire-9 (PHQ-9). Arthritis Care Res (Hoboken). https://doi.org/10.1002/acr.20556

9. Creamer M, Bell R, Failla S (2003) Psychometric properties of the Impact of Event Scale-Revised. Behav Res Ther. https://doi. org/10.1016/j.brat.2003.07.010

10. Morina N, Ehring T, Priebe S (2013) Diagnostic utility of the impact of event scale-revised in two samples of survivors of war. PLoS ONE. https://doi.org/10.1371/journal.pone.0083916

11. Aydemir O, Guvenir T, Kuey L, Kultur S (1997) Validity and reliability study of the hospital anxiety and depression scale Turkish form. Turkish J Psychiatr 8:280-287

12. Çorapçioğlu A, Yargiç İ, Geyran P, Kocabaşoğlu N (2006) Olaylarin Etkisi Ölçeği (IES-R) Türkçe versiyonunun geçerlilik ve güvenilirliği. New/Yeni Symposium: psikiyatri, nöroloji ve davraniş bilimleri dergisi 44:14-22

13. Mazza C, Ricci E, Biondi S et al (2020) A nationwide survey of psychological distress among italian people during the COVID19 pandemic: immediate psychological responses and associated 
factors. Int J Environ Res Public Health. https://doi.org/10.3390/ ijerph17093165

14. Wang $C$, Pan $R$, Wan $X$ et al (2020) Immediate psychological responses and associated factors during the initial stage of the 2019 coronavirus disease (COVID-19) Epidemic among the general population in China. Int J Environ Res Public Health. https:// doi.org/10.3390/ijerph17051729

15. Zhang WR, Wang K, Yin L et al (2020) Mental health and psychosocial problems of medical health workers during the COVID-19 Epidemic in China. Psychother Psychosom. https:// doi.org/10.1159/000507639

16. Tolin DF, Foa EB (2006) Sex differences in trauma and posttraumatic stress disorder:a quantitative review of 25 years of research. Psychol Bull. https://doi.org/10.1037/0033-2909.132.6.959

17. Lei L, Huang X, Zhang S, et al (2020) Comparison of Prevalence and Associated Factors of Anxiety and depression among people affected by versus people unaffected by quarantine during the COVID-19 epidemic in southwestern China. Med Sci Monit. https ://doi.org/10.12659/MSM.924609

18. Gao J, Zheng P, Jia Y et al (2020) Mental health problems and social media exposure during COVID-19 outbreak. PLoS ONE. https://doi.org/10.1371/journal.pone.0231924

19. Garfin DR, Silver RC, Holman EA (2020) The novel coronavirus (COVID-2019) outbreak: Amplification of public health consequences by media exposure. Health Psychol. https://doi. org/10.1037/hea0000875

20. Ni MY, Yang L, Leung CMC et al (2020) Mental Health, Risk Factors, and Social Media Use During the COVID-19 Epidemic and Cordon Sanitaire Among the Community and Health Professionals in Wuhan. Cross-Sectional Survey. JMIR Ment Health, China

21. Chung BPM, Wong TKS, Suen ESB et al (2005) SARS: caring for patients in Hong Kong. J Clin Nurs. https://doi.org/10.111 1/j.1365-2702.2004.01072.x

22. Kim Y (2018) Nurses' experiences of care for patients with Middle East respiratory syndrome-coronavirus in South Korea[J]. Am J Infect Control. https://doi.org/10.1016/j.ajic.2018.01.012

23. Khalid I, Khalid TJ, Qabajah MR et al (2016) Healthcare worker semotions, perceived stressors and coping strategies during MERS-CoV outbreak. Clin Med Res. https://doi.org/10.3121/ cmr.2016.1303

24. Liu C, Wang H, Zhou L et al (2019) Sources and symptoms of stress among nurses in the first Chinese anti-Ebola medical team during the Sierra Leone aid mission: A qualitative study [J]. Int J Nurs Sci. https://doi.org/10.1016/j.ijnss.2019.03.007

25. Galea S, Nandi A, Vlahov D (2005) The epidemiology of posttraumatic stress disorder after disasters. Epidemiol Rev. https:// doi.org/10.1093/epirev/mxi003

26. Dutheil F, Mondillon L, Navel V (2020) PTSD as the second tsunami of the SARS-Cov-2 pandemic. Psychol Med. https://doi. org/10.1017/S0033291720001336

27. Mak IW, Chu CM, Pan PC et al (2009) Long-term psychiatric morbidities among SARS survivors. Gen Hosp Psychiatry. https ://doi.org/10.1016/j.genhosppsych.2009.03.001

28. Lee AM, Wong JG, McAlonan GM (2007) Stress and psychological distress among SARS survivors 1 year after the outbreak. Can J Psychiatry. https://doi.org/10.1177/070674370705200405

29. Lancee WJ, Maunder RG, Goldbloom DS (2008) Coauthors for the Impact of SARS Study. Prevalence of psychiatric disorders among Toronto hospital workers one to two years after the SARS outbreak. Psychiatr Serv. https://doi.org/10.1176/ps.2008.59.1.91

30. Hawryluck L, Gold WL, Robinson S et al (2004) SARS control and psychological effects of quarantine. Emerg Infect Dis, Toronto

31. Reynolds DL, Garay JR, Deamond SL et al (2008) Understanding, compliance and psychological impact of the SARS quarantine experience. Epidemiol Infect. https://doi.org/10.1017/S095026880 7009156

32. Peng EY, Lee MB, Tsai ST et al (2010) Population-based postcrisis psychological distress: an example from the SARS outbreak in Taiwan. J Formos Med Assoc. https://doi.org/10.1016/S0929 $-6646(10) 60087-3$

33. Huang J, Liu F, Teng Z et al (2020) Care for the psychological status of frontline medical staff fighting against COVID-19. Clin Infect Dis. https://doi.org/10.1093/cid/ciaa385

34. Huang Y, Zhao N (2020) Generalized anxiety disorder, depressive symptoms and sleep quality during COVID-19 outbreak in China: a web-based cross-sectional survey. Psychiatry Res. https://doi. org/10.1016/j.psychres.2020.112954

Publisher's Note Springer Nature remains neutral with regard to jurisdictional claims in published maps and institutional affiliations. 